\title{
Enhancing Project Experiences of IT Students: The Role of Supervisors
}

\author{
Shariq Ali Khan ${ }^{1}$, Muhammed Nauman Bashir ${ }^{2}$ \\ ${ }^{1}$ Department of Computing Middle East College, Knowledge Oasis, Oman \\ ${ }^{2}$ Department of Electronics Engineering Middle East College, Knowledge Oasis, Oman \\ shariq@mec.edu.om,mbashir@mec.edu.om
}

\begin{abstract}
This paper describes how the role of supervisors is critical to success of students' project. It emphasizes the need for supervisors to move from conventional project supervision to assuming multiple roles in order to enhance student experience. The present study is a reflection of the authors, emphasizing the critical role of the supervisors in a changing environment in the higher education sector- especially with the increasing pressure on students while on projects, varying nature of quality assurance adopted by higher education institutions and the competitive environment in which institutions operate. The study is based on the lived experiences of the authors, their students and colleagues, and those that have emerged from informal discussions with academic staff in institutions offering similar programs. The proposals suggested in various sections are also based on the success of some the initiatives in which the authors were engaged, in their institution.
\end{abstract}

Index Terms - Computer Education, Student Projects, role of supervisors.

\section{Introduction}

Project is an important component in the present day curricula. It provides opportunities for students to work in teams, analyzing industry requirements, and manage different tasks. Students find projects challenging and exciting, as it forces them to become independent learners and helps them to be more focused to apply the knowledge and skills to achieve their project goals. In the process, students not only increase their employability but also develop transferable skills and enhance professional competence.

In the case of IT students, projects are unique for several reasons. Often IT students work on unfamiliar platforms or new suites that have no linkages to the modules in their programs. They may have to work on applications for which testing may not be possible or testing may fail. In order to exploit the potentials of IT, projects must integrate a broad spectrum. This requires understanding a variety of subject areas. It is not uncommon to see IT projects that integrate commerce, medicine, and communication with technology. Range of applications, testing environments, and infrastructure and other academic support required for smooth completion of project add to the complexities of an IT project.

Increasing expectations from IT students, specialized nature of projects, and the demands placed by institutions and employers have redefined the role of academic staff involved in project guidance. Though projects are student led, academic staff finds it important to engage themselves at various stages of the project beyond traditional supervision. From helping students to have the right composition of team members to preparing them to effectively present their project outcomes, project supervisors have important role for smooth completion of projects. Supervisors are thus collaborators, advisers, and mentors. They are integral part of the project team. All these have implications for the students and academic staff involved in the project. Several studies have been reported in relation to student projects on range of topics. The need for tutors to engage in learning and teaching to re-think and refine issues such as transparency of assessment, meaningful feedback, open discussion and explicit marking criteria has been explored in [7]. Strategies on how to improve projects, based on data collected from students working on programming projects, is reported in [5]. Difficulties of designing and running a final year project course, for computer science and information systems students, are reported in [6]. The need to understand the benefits of collaborative learning in a group work and the role of faculty in emphasizing its importance to students has been explored in [1].

Diversity of opinion among staff and students about various issues surrounding under graduate research projects and the need to establish a climate of open dialogue between staff and students, to share various elements related to learning and assessment has been emphasized in [8]. The role of supervisor and the mechanisms that may be used to develop competencies among students, in areas such as group dynamics, communication, organization and project management, have been discussed in [4]. How the supervisor can take the role of a guide suggesting alternatives but allowing the student to ultimately find their own way has been explored in [2]. Reviewing some models for independent study and project work and examining for continuities or differences between independent study and project work, a new model, wherein differences are primarily a matter of degree and its value in relation to project work is outlined in [3].

\section{IT Projects: Balancing Academic Standards and Industry Requirements}

Most IT projects are designed and developed to meet the specific needs of a company. IT students and their supervisors are keen on working with real time projects. Even in projects that result in toolsets, software packages, and operating systems, testing scenarios from an industrial setting are 
required. Institutions believe that projects with industry linkages will help students understand the work culture in an organization and minimize the learning curve required during employment.

Industry perception and academic requirements of an IT project vary. IT companies emphasize on successful development of market-friendly and quality products. They can afford to have projects with huge costs and large number of people, involving several man-days. Their financial strengths enable them to hire and train staff at high cost, import software and other equipment, and manage large teams and complex projects. On the other hand academic institutions emphasize that students should demonstrate competence in a range of attributes. Moreover, financial affordability of students is limited. Academic setting emphasizes team building, communication skills, exposure to a professional setting, and ability to develop manuals and other project documents as important learning outcomes for an IT project. With such varying expectations the role of project supervisor becomes more important, especially when students do real time project.

Often successful student groups have pressure from the companies to go beyond the scope of their projects and develop robust IT products instead of stopping once their project goals are achieved. With such involvement, students are unable to meet academic requirements such as mid-term presentation, interim submission of documentations relating to project requirements, synopsis of work done and progress made by the team. In such situations, supervisors will have to take control, and prevent students from continuing with the project and remind them of their academic obligations.

A strong link between the supervisor and the industry will go a long way strengthening both the academic component as well as the industry elements from an IT project perspective. Supervisor's interaction with the company will help them understand the general criteria that all projects should satisfy, requirements that are specialization specific, and the characteristic that differentiate a Diploma project from a Bachelors project. Formal and informal meetings with industry collaborators will help supervisor make informed decisions about the possible role and scope of the projects, its acceptability in the industry, and related job opportunity. In their urge to enhance the quality of programs in general and projects in particular, the academic community increase the demands placed on students and their projects. All such initiatives must be realistic, sustainable, and appropriate from an industry perspective as well. Otherwise, students will be caught between industries that work with client needs and profit motive and academia that work with a different culture.

\section{Supervisors' Feedback: A Critical Success Factor for IT Projects}

Constant feedback on the progress of work and possible areas where the student should pay more attention to is important for the smooth completion of projects. Response to students can be in several ways and can be a consequence of formal and informal interaction and presentation. With regular feedback from supervisors, students will focus on improving the quality of project rather than seeking high grades.

Project students without regular feedback are frustrated when they find their final grades below their expectations. They believe that their effort was not recognized, the project report did not yield them the desired marks despite interventions from languages specialists (in situations where English language related issues become important), and their presentation/viva-voce was not considered while making a decision on the strength of the projects. Effectively, students believe that no effort was put in by examiners to understand the project. They also begin to believe that their supervisor misled them and assume that their supervisor is responsible for their failure.

Student anxieties can be avoided if the supervisor provides critical feedback at various stages of the project. There should be a systematic feedback mechanism across all groups of students involved in a project. Students not only need comments but also guidance to rework on their initial proposal. Often they will not be able to develop clear objectives of the project and are guided by wishful thinking. Timelines is another area where they may not be realistic. Supervisors will have to help students recognize missing elements in their project and work with them to shape the project. A user friendly database that contains details of progress made by each student and the teams will help supervisor know the status of the project online. With an appropriate toolset they could provide comments and at times remind students that there is no progress of their work. Supervisor can also test the code that students might write or other tools that they may be developing, with available software and hardware.

Feedback is not one way and does not terminate with responses from the supervisor. Students' response to feedback is bound to trigger a range of issues. Sometimes it might even result in curriculum changes, help supervisor define a new strategy to strengthen projects, and identify possible administrative issues relating to lab and other practice sessions. For best gains and successful engagement between the supervisor and student the flow of information and feedback mechanism should be along the lines of a water fall model, wherein inputs from students and feedback from supervisor is a continuous process, with every stage resulting in enhancement of the project.

\section{Enhancing English Language Capabilities and Project Management Skills}

Often IT students focus on developing their IT related skills. They show interest in programming languages and tools, new chips and other peripheral devices that are being developed, and emerging opportunities in IT field worldwide. They surf the internet, use the library, test run some applications with available beta versions, talk to peers and experts to understand the ongoing developments. But they 
have limited opportunities to understand and develop project management capabilities. Their English language capabilities and project management skills are also usually limited as compared to their technical skills.

Students find that insufficient English language proficiency is a barrier at various stages of the project. Inability to read manuals and books on topics of their project interest at early stages creates frustration among students. With clients from a global market, IT related jobs require strong communication and effective presentation skills. Students must have these skills and a reality check on the same is done while students do their projects. Unable to present their ideas and project goals to prospective industrial collaborators students sometimes miss the chance of working on prestigious projects. Limited writing skills often drive students to choose development and implementation over documentation of their project. As a consequence, students are not able demonstrate their efforts and accomplishments to anybody outside their team or external to IT domain.

High attrition rates in the IT sector, sensitivity and complexity of real time projects, and risk and returns associated with projects necessitate employees in the IT industry to have adequate project management skills. Except for some modules and software tools on project management, IT students have limited practical knowledge. Hence when there are deviations to their original plans, they are not able to take charge, overcome hurdles, and complete their project successfully. When there is a change in the expected resources, or team members fail to cooperate they are unable manage and see through their projects successfully.

Project supervisors will have to impress upon students that project management skills, language capabilities, and technical expertise are important and need to be integrated for successful completion of IT projects. All the three have to be built across the curriculum. With appropriate assessment strategies and formal and informal instruction supervisors must find ways of providing English language skills. More precisely the key skills viz. reading, writing, listening and speaking must be embedded across the curriculum.

Language skills and project management are two key areas wherein IT students will have to focus starting from their enrollment on program. Supervisors will have to make institution wide influences to ensure that these two skills are ingrained in various ways in the teaching and learning process. Introducing additional modules for this purpose will only add to the load of the student and defeat the purpose.

\section{Overcoming Administrative Obstacles with Supervisors Support}

Bureaucracy and administrative hurdles outside and within the institutions lead to frustrating experiences for project students. Often, when IT students seek permission to access sensitive data, they are confronted with lengthy procedures and are forced to answer a volley of questions.
Reliance on traditional and lengthy procedures is potential irritants to the progress of projects. Students also become victims when administrative procedures dominate academic interest and subject specialization in the choice of supervisor and nature of projects. In team projects, students face difficulties when departmental regulations determine the composition of teams. When IT projects integrate a broad spectrum, students require support from academic staff across departments to understand concepts that are not IT based. They may also require access to labs and resources from other institutions. In such situations, students may end up spending substantial time in resolving procedural wrangles.

Often students have no knowledge about the resources such as software, hardware, and computer time required before they start the project. They are not aware of the possible consequences of time restrictions and financial constraints. They realize the requirements as the projects progress. Students working on inter-disciplinary projects may require different tools, lab equipment, and learning resources. Students require transportation to work during odd hours and to visit industry. In order to preserve the documents and other equipment they require sufficient space. Areas to take a break from continuous work on project and comfortable eateries are also required. With support from supervisors, students can cross administrative hurdles within and outside the institution. Supervisors can influence the departments and the institutions to support students in various ways. Simplifying the procedures and eliminating the need for exhaustive documentation supervisors can find ways of assessing student participation in the project. Providing fair and safe access to resources will keep students away from guessing a wish list of resources and help them focus on their projects. Working across different academic support units within the institution, supervisors could help students enhance their experience on campus while doing their projects.

Supervisors must constantly interact with government bodies, academic groups, and other authorities to develop strong external linkages. The importance of project and ways in which different bodies could help should be discussed in different forums. Institution should have memoranda of understanding and other agreements with government bodies and the private sector for information sharing and utilization of available resources.

Supervisors must make use of the services of professional bodies at regional and international levels to sort issues relating to technical support. IT projects are time bound and sensitive. They require support at various levels and forms. Delays at any stage will harm the progress of the project. Supervisors can form a strong link between administrative arm of the institutions and the students and thus bring down the tensions. They can also promote students' case to external bodies. 


\section{Understanding the Demands of Project: Orientation as Communication Channel for Supervisor}

Lack of clarity, inability to understand different regulations and rules, and incorrect perceptions on projects often develop tension among students, institution, and supervisors. Time, money, and effort are lost when students realize that their projects do not meet the requirements or that they have not followed important administrative procedures. Effective orientation program will help students understand the demands of an IT project, its uniqueness, and the preparations required to address possible challenges. Supervisors could make use of the orientation to communicate the importance of project, different stages of project development and management, methods to promote team work and help students enhance their skills. With the help of projects done in the past, supervisors must help students understand how a successful project can be developed. They should also encourage students to do projects in new domains and cross platforms.

IT students are anxious about the success of their projects. From the inception stage through the implementation stage they often believe that the projects must be successful and that the end product should be functional. This is not necessarily true. Academic projects are different from commercial projects which have to necessarily address the clients' requirements. The emphasis on academic projects is to ensure that students are able to apply different concepts that they learn to a practical situation efficiently.

Level of engagement, by a student, required for a project needs to be explained to a student. Engagement in projects is different from preparations for other modules. The number of hours spent on different tasks does not really count for the success of the project or the grades that a student is awarded. A well-documented project report or skillful presentation will not be an evidence of understanding. Student's effort in working towards the project objectives and the skills and knowledge obtained in the process is important.

Culturally sensitive issues need to be handled with care. Students may have to talk to opposite genders and members in the society who hold influential position. Students may not be strong in interpersonal relationships. Hence supervisors must help students to recognize the importance of the same; to uphold and respect the traditions and culture of the country, to follow industry etiquette, and to pay attention to body language.

\section{Conclusion}

Notwithstanding the collaborative role of the supervisor, the student should be driving the project. Institutions, parents and students, and the industry must understand that ownership of the project lies with the student and the supervisor plays multiple roles only to enhance the quality of project. Efforts from the supervisor stems from a professional commitment to the academic community, concern for the students, and interest to contribute to the body of knowledge. Student groups must consider supervisor's comments and suggestions as valuable clues for improvement and make an independent analysis on the status of their project at various stages of progression. Supervisors' comments cannot and should not be quoted to justify changes made or when failures occur. It is not the responsibility of the supervisor to keep track of students' progress and ensure that projects are successful. If institutions emphasize such agenda, then the character of projects as independent piece of student effort will be lost.

\section{Acknowledgment}

The authors place on record their deep sense of gratitude to their colleagues and students in their institution and other institutions in the Sultanate of Oman, who were engaged in student project for their contribution in preparing this paper.

\section{References}

[1] Barker, L. J.(2005) When do Group Projects Widen the Student Experience Gap? Proceedings of the 10th annual SIGCSE conference on Innovation and technology in Computer Science Education, Caparica, Portugal, pp.276-280.

[2] Clark, M.A.C., and Boyle ,R.D. (1999), A Personal Theory of Teaching Computing Through Final Year Projects, Computer Science Education ,9( 3), pp. 200-214.

[3] Cuthbert, K. (2001), Independent Study and Project Work: continuities or discontinuities, Teaching in Higher Education, 6(1), pp.69-84.

[4] Hansen, S.(2004) The supervisor in the project- organized group work should participate in developing the students' project competencies, European Journal of Engineering Education,29(3), pp.451- 459 .

[5] Hansen, S., and Eddy, E., (2007) Engagement and Frustration in Programming Projects, Proceedings of the 38th SIGCSE technical symposium on Computer Science Education, Covington, Kentucky, USA., pp.271-275.

[6] Olsson, B., Berndtsson, M., Lundell, B., and Hansson, J. (2003) Running Research-Oriented Final Year Projects for CS and IS Students, Proceedings of the 34th SIGCSE technical symposium on Computer Science Education,Reno, Nevada, USA, pp.79-83.

[7] Orsmond, P., Merry, S., and Reiling, K. (2004), Undergraduate project work: can directed tutor support enhance skills development? Assessment \& Evaluation in Higher Education, 29 (5), pp, 625-642

[8] Stefani, L. A. J., Tariq, V. N., Heylings, D. J. A., and Butcher, A. C.(1997), A Comparison of Tutor and Student Conceptions of Undergraduate Research Project Work, Assessment \& Evaluation in Higher Education,22(3), pp.271- 288. 